\title{
Use of inline measures of L-lactate dehydrogenase for classification of posttreatment mammary Staphylococcus aureus infection status in dairy cows
}

\author{
C. Hildebrandt Jørgensen, ${ }^{* 1}$ A. R. Kristensen,† S. Østergaard, ${ }^{*}$ and T. W. Bennedsgaard* \\ *Department of Animal Science, Aarhus University, DK-8830 Tjele, Denmark \\ †Department of Large Animal Sciences, University of Copenhagen, DK-1870 Frederiksberg C, Denmark
}

\section{ABSTRACT}

An automated method for determining whether dairy cows with subclinical mammary infections recover after antibiotic treatment would be a useful tool in dairy production. For that purpose, inline L-lactate dehydrogenase (LDH) measurements were modeled using a dynamic linear model; the variance parameters were estimated using the expectation-maximization algorithm. The method used to classify cows as infected or uninfected was based on a multiprocess Kalman filter. Two learning data sets were created: infected and uninfected. The infected data set consisted of records from 48 cows with subclinical Staphylococcus aureus infection from 4 herds collected in 2010. The uninfected data set came from 35 uninfected cows collected during 2013 from 2 herds. Bacteriological culturing was used as gold standard. To test the model, we collected data from the 48 infected cows $50 \mathrm{~d}$ after antibiotic treatment. As a result of the treatment, this test data set consisted of 25 cows that still had a subclinical infection and 23 cows that were recovered. Model sensitivity was $36.0 \%$ and specificity was $82.6 \%$. To a large extent, L-lactate dehydrogenase reflected the cow's immune response to the presence of pathogens in the udder. However, cows that were classified correctly before treatment had a better chance of correct classification after treatment. This indicated a variation between cows in immune response to subclinical mammary infection that may complicate the detection of subclinically infected cows and determination of recovery.

Key words: dairy cow, mastitis, L-lactate dehydrogenase, multiprocess model

\footnotetext{
Received January 5, 2016.

Accepted June 16, 2016.

${ }^{1}$ Corresponding author: carina.jorgensen@anis.au.dk
}

\section{INTRODUCTION}

Intramammary infections in dairy cows are of great concern to the dairy industry (Bradley, 2002). Staphylococcus aureus is a common cause of such infections. It is highly contagious, and the majority of infections are subclinical (Barkema et al., 2006). For this reason, it is important for farmers to know which of their cows are infected. To keep transmission low, infected cows should be treated with antibiotics or separated from healthy cows (Lundberg, 2015), but this is possible only if infections can be detected with measures of sufficient quality. Conventional methods for determination of whether or not bacteria are present are bacteriological culturing or PCR analysis of milk samples. These methods are very time consuming because milk samples from individual cows are needed and cows' infection status should be updated regularly. The aim of the present study was to develop an automated method for detecting pathogens in dairy cow udders based on inline L-lactate dehydrogenase ( $\mathbf{L D H})$ measurements.

Traditionally, monitoring in animal production has been based on select static key figures isolated in time, such as milk production per cow or average daily gain in slaughter pigs. Observed key figures are interpreted as a true underlying value plus random variation and compared with a predefined target. The fundamental assumption behind this approach is that the true underlying mean is constant over the period of interest. However, in animal production, the underlying mean will often show some kind of variation. This variation can be accounted for when a time series of measurements is available (Kristensen et al., 2010). Therefore, time series are also very well suited to measuring milk quality and pathogens in milk.

Dynamic monitoring of time series has become an important tool in different areas such as medicine and finance, and this technique has found use in animal production. For instance, Thysen (1993) monitored milk quality in dairy cows, Roush et al. (1992) detected changes in feed consumption in broilers, and de Mol et 
al. (1999) and Cornou and Lundbye-Christensen (2008) detected estrus and disease in dairy cattle and sows, respectively. With inline monitoring, level shifts can be detected in real time as new observations are made. However, to use the continual stream of measurements, a framework that allows knowledge to accumulate is needed. Mathematical and statistical modeling of time series processes can be based on classes of state space models, also called dynamic models.

Technological development has made it possible to conduct automatic inline sampling and measurement of components in milk. The enzyme LDH is found in the cytoplasm of all cells in the body, and during an inflammatory process involving cell damage and breakdown, as observed during IMI, it is released from the cell into the milk (Zank and Schlatterer, 1998). In dairy milk, LDH is correlated with SCC (Chagunda et al., 2006a; Akerstedt et al., 2011; Nyman et al., 2016), and it is used as a mastitis indicator in commercial herd management (Chagunda et al., 2006b; Friggens et al., 2007). The aim of the present study was to develop a model that could classify cows correctly according to their true infection status after antibiotic treatment.

\section{MATERIALS AND METHODS}

\section{Herds and Data Collection}

In this study, we included 2 data sets. The first included only cows infected with Staph. aureus, and the second included only uninfected cows.

We collected data set 1 during the autumn of 2010; it contained data from 4 dairy herds that were chosen because they used the Herd Navigator management program (DeLaval, Tumba, Sweden). All cows were housed in freestall barns with cubicles. Two herds used automatic milking systems and 2 herds used milking parlors. The predominant breed was Holstein. Herd characteristics are presented in Table 1.

The aim of the data collection was to evaluate milk bacteriology and LDH concentration in milk before and after antibiotic treatment in cows infected with Staph. aureus. Cows that were likely to have chronic IMI were selected for screening of milk samples (209 cows). Selected cows had a SCC $>100,000$ cells $/ \mathrm{mL}$ in the latest monthly test recording or a SCC $>150,000$ cells $/ \mathrm{mL}$ in at least 1 of 2 consecutive milk recordings in the present lactation. Cows were not eligible for the screening if they (1) had received antimicrobial treatment in the $11 \mathrm{~d}$ before enrollment; (2) were expected to be culled, sold, or dried off during the trial; (3) had fewer than 3 lactating quarters; or (4) was over 250 DIM. The 3 latter groups were not expected to stay in the herd for the $56 \mathrm{~d}$ required for the trial. After the above-described selection of cows, data set 1 included 48 cows.

Quarter milk samples were collected on 2 or 3 occasions from each cow for bacteriological culture before initiation of treatment on $\mathrm{d} 0$. The time between sampling was at least 1 week, and the time between last sampling and therapy was $14.2 \pm 6.75 \mathrm{~d}$. If only 1 of the first 2 samplings was Staph. aureus positive, an additional sample was collected. Cows were considered infected when at least 1 of the quarter samples was Staph. aureus positive. All samples were collected either by veterinary students or veterinarians employed by the Faculty of Agricultural Science, Aarhus University (Tjele, Denmark).

Aseptic samples for bacteriology were collected after disinfection of the teat ends with cotton swabs soaked in $70 \%$ alcohol and the first few milliliters of milk were discarded; samples were collected in sterile plastic tubes. Latex gloves were worn during sample collection. Samples were stored in a freezer at $-18^{\circ} \mathrm{C}$ until they were thawed for culturing.

Laboratory examinations were performed as follows: an inoculum of $0.02 \mathrm{~mL}$ of milk was cultured on blood agar plates supplemented with esculin, and on ChromID Staph. aureus medium (bioMérieux, Marcy l'Etoile, France). Plates were incubated at $37^{\circ} \mathrm{C}$ for 18 to $24 \mathrm{~h}$. Identification was based on colony morphology and biochemical tests. Strains producing double hemolysis were presumed to be Staph. aureus, and the

Table 1. Description of the 5 participating herds

\begin{tabular}{|c|c|c|c|c|c|c|c|}
\hline $\begin{array}{l}\text { Herd } \\
\text { no. }\end{array}$ & $\begin{array}{l}\text { Herd } \\
\text { size }\end{array}$ & \multicolumn{2}{|c|}{ No. of cows } & Cow breed & $\begin{array}{c}\text { Milk yield } \\
(\mathrm{kg} \text { of } \mathrm{ECM} / 305 \mathrm{~d})\end{array}$ & Milking system ${ }^{1}$ & $\begin{array}{l}\text { Bulk tank SCC } \\
\left(\times 10^{3} \text { cells } / \mathrm{mL}\right)\end{array}$ \\
\hline $1 \mathrm{a}$ & 240 & 5 & - & Holstein & 9,600 & Voluntary milking system & 167 \\
\hline 2 & 120 & 31 & - & Holstein & 9,100 & Milking parlor & 216 \\
\hline 3 & 140 & 3 & - & Holstein & 9,300 & Milking parlor & 199 \\
\hline 4 & 100 & - & 18 & Holstein & 10,300 & Milking parlor & 119 \\
\hline
\end{tabular}

${ }^{1}$ Both the voluntary milking system and the milk parlor were from Herd Navigator (DeLaval, Tumba, Sweden). 
diagnosis was further confirmed if the strain produced a green color on the ChromID Staph. aureus medium. Catalase-positive colonies with incomplete hemolysis were selected for further testing. Suspected Staph. aureus were confirmed as positive using the Slidex Staph Plus test (bioMérieux) or, if still negative, a tube coagulase test was performed to confirm the case. The sample was considered positive when growth of at least $1 \mathrm{cfu}$ of Staph. aureus was detected.

Laboratory bacteriological analyses were performed by trained technicians employed by the Faculty of Agricultural Science, Aarhus University (Tjele, Denmark) and 2 veterinary students under supervision of trained technicians. The results from the cultures were used as the gold standard for Staph. aureus infection status.

Cows fitting the inclusion criteria were randomly allocated to 1 of the following 3 groups: (1)

- Group 1 (15 cows): $20 \mathrm{mg}$ of penethamate hydriodide (Mammyzin; Boehringer Ingelheim, Kalundborg, Denmark) per kg of BW, delivered i.m. in combination with intramammary administration of $600,000 \mathrm{IU}$ of benzylpenicillin procaine (Carepen; Boehringer Ingelheim) in all udder quarters, repeated every $24 \mathrm{~h}$ for $5 \mathrm{~d}$;

- Group 2 (16 cows): intramammary administration of $600,000 \mathrm{IU}$ of benzylpenicillin procaine in all udder quarters, repeated every $24 \mathrm{~h}$ for $5 \mathrm{~d}$; or

- Group 3 (17 cows): no treatment.

On each farm, at least 2 treatment regimens were carried out. Treatment was initiated on d 0 , and followup visits with collection of samples for bacteriology were carried out on d 7, 14, 28, and 56 after therapy. Samples for bacteriology were conducted and analyzed in the same way as before the start of the trials.

Data set 2 was collected during the autumn 2013 to evaluate $\mathrm{LDH}$ concentration and variation in uninfected cows. Originally, 44 cows from 2 of the 4 herds described above were selected based on a low SCC in milk (SCC $<100,000$ cells/mL in all monthly tests in the present lactation). In addition, these cows had no mastitis alarms in the Herd Navigator system and no mastitis treatments in the previous lactation. Two milk samples from each cow were taken and cultured $1 \mathrm{wk}$ apart. Samples for bacteriology were conducted and analyzed in the same way as described for data set 1 . Only cows with 2 consecutive negative culture results were included in the final data set. After selection, data set 2 included 35 cows. Cows were in different lactation stages at the time of testing, but all were more than 30 DIM.

\section{Inline Measurements of LDH}

The LDH data used in the present study were similar to normal output data from the Herd Navigator system, so they were corrected using the procedure described below. In the Herd Navigator system, LDH activity values ( $\mu \mathrm{mol} / \mathrm{min}$ per liter) were measured using dry-stick technology. During milking, a representative milk sample was taken automatically, and $10 \mu \mathrm{L}$ of the milk was applied to the indicator stick. The enzymatic reaction with $\mathrm{LDH}$ was coupled to a color dye, and the intensity of the color reaction after application of the milk sample was measured using a digital camera. The raw measurements were corrected according to company-standardized methods to account for variations in surrounding humidity and differences between batches of dry sticks. Then, the most extreme outliers were removed. Measurements exceeding $200 \mu \mathrm{mol} / \mathrm{min}$ per liter were set to a maximum value of 200 , and all negative values were deleted, because they were not in accordance with the normal range of measurements obtained from the Herd Navigator system. This editing of data is normal for data from the Herd Navigator system.

Milk yield at the cow level was measured using an optical milk meter. The LDH concentration ( $\mu \mathrm{mol} /$ min) was calculated as the LDH activity divided by the milk yield from the individual milking.

\section{Multiprocess Kalman Filter}

We modeled time series of LDH measurements from cows with and without episodes of subclinical Staph. aureus mastitis using a dynamic linear model (DLM) combined with a Kalman filter (Kalman, 1960). We used the simplest form of a DLM, also known as a first-order polynomial DLM (West and Harrison, 1997). It is entirely specified by 2 variance components, $V_{t}$ and $W_{t}$. Based on LDH measurements from cows with known infection status, variance components for the 2 DLM (infected and uninfected) were estimated using the expectation-maximization algorithm. We assumed that LDH measurements showed 2 different patterns (i.e., 2 different sets of variance components) depending on whether or not the cow was infected. We based the classification of LDH measurements by infection status on a multiprocess Kalman filter (West and Harrison, 1997).

\section{Selection of Infection Status and Associated Time Series}

To model and classify the infection status of individual cows, we used 2 learning data sets and a test 
data set. The learning data set "infected" consisted of measurements from all cows in data set 1 from $d-50$ to $\mathrm{d} 0$ relative to $\mathrm{d}$ of treatment. Data represented the infected cows. The learning data set "uninfected" consisted of measurements from the cows in data set 2 , in a 5-wk period, from $28 \mathrm{~d}$ before the first culture to the last culture. The test data set consisted of measurements from all cows in data set 1 from d 0 to 50 relative to day of treatment. Data were used as test data set for validation of the classification method.

\section{Model Design}

The first-order polynomial DLM was specified by 2 equations: the observation equation [1] and the system equation [2] (West and Harrison, 1997). The observation equation described the data observed by a vector of parameters $\boldsymbol{\theta}_{t}$ combined with a random term. The observation equation describes the data observed $\left(Y_{t}\right)$ by a vector of parameters $\boldsymbol{\theta}_{t}$ combined with a random term $\left(\nu_{t}\right)$. The system equation describes the dynamic properties of the parameters $\boldsymbol{\theta}_{t}$ :

$$
\begin{gathered}
Y_{t}=\boldsymbol{\theta}_{t}+v_{t}, v_{t} \sim N\left(0, V_{t}\right), \\
\boldsymbol{\theta}_{t}=\boldsymbol{\theta}_{t-1}+w_{t}, w_{t} \sim N\left(0, W_{t}\right) .
\end{gathered}
$$

Error sequences $v_{t}$ and $w_{t}$ were assumed to be internally and mutually independent, with mean 0 and known variances $V_{t}$ and $W_{t}$, respectively. In the present study, we assumed a constant observational variance so that $V_{t}=V$.

The DLM combined with a Kalman filter (Kalman, 1960) estimated the underlying state vector $\boldsymbol{\theta}_{t}$ by its conditional mean vector $\mathbf{m}_{t}$ and its variance-covariance matrix $\mathbf{C}_{t}$, given all previous $\mathrm{LDH}$ observations $D_{t}=$ $\left\{Y_{1}, \ldots, Y_{t}\right\}$. In other words, the conditional distribution of $\boldsymbol{\theta}_{t}$ was

$$
\left(\boldsymbol{\theta}_{t} \mid D_{t}\right) \sim N\left(\mathbf{m}_{t}, \mathbf{C}_{t}\right) .
$$

The updating equations of the Kalman filter we used for stepwise calculation of $\mathbf{m}_{t}$ and $\mathbf{C}_{t}$ can be found in West and Harrison (1997).

Because the number of measurements of LDH depended on the risk of infection calculated in the Herd Navigator system, the number of observations varied between cows. Therefore, we extended the DLM framework to handle the unequal interval between LDH measurements. This means that a constant system variance $W$ was multiplied by the time interval $\left(d_{t}\right)$ since the last observation
$W_{t}=d_{t} W$

\section{Estimation of Variance Parameters}

The observation variance $V$ and the system variance $W$ for the 2 states (infected and uninfected) were estimated using the expectation-maximization algorithm. It estimates unknown parameters by maximum likelihood estimation, using the conditional mean vector $\mathbf{m}_{t}$ and the model variance $\mathbf{C}_{t}$ from Kalman filtering and their respective smoothed components $\tilde{\mathbf{m}}_{t}$ and $\tilde{\mathbf{C}}_{t}$ obtained after smoothing (West and Harrison, 1997). Following this procedure, 2 DLM were defined, one $\left(M_{1}\right)$ representing the infected state and the other $\left(M_{2}\right)$ representing the uninfected state. The 2 DLM are each described by a tuple, so that $M_{1}:\left\{V_{1}, W_{1}\right\}$ and $M_{2}:\left\{V_{2}, W_{2}\right\}$. We implemented the DLM and the expectation-maximization algorithm from scratch using the $\mathrm{R}$ software system (R Core Team, 2013).

\section{Classification}

To determine which of the 2 DLM best described the observations in the test data set, we applied a class I multiprocess DLM, in which a single DLM is viewed as appropriate for describing the entire time series, but there is uncertainty as to which one. We analyzed a time series of measurements from each cow using the updating equations of the Kalman filter. At each observation time $t$, we calculated the model 1-step forecast mean $f_{t}$ and the corresponding variance $Q_{t}$. Thus, after each new observation, we updated the previous probability to obtain posterior probabilities from which the observations from a specific cow belonging to the infection DLM were estimated. The initial probability was set to 0.5 .

\section{Model Evaluation}

The success criterion was to develop a model that could classify cows correctly as infected or uninfected when compared with culture results (gold standard). We used a threshold of 0.5 to distinguish between infected and uninfected cows. The outcomes were summarized as follows:

True positive $(\mathbf{T P})=$ number of infected cows classified as infected;

False negative $(\mathbf{F N})=$ number of infected cows classified as uninfected;

False positive $(\mathbf{F P})=$ number of uninfected cows classified as infected; 
True negative $(\mathbf{T N})=$ number of uninfected cows classified as uninfected.

Using these basic classifications, we were able to evaluate the performance of the model by means of sensitivity and specificity. Sensitivity refers to the probability that an infected cow will be classified as such, and specificity refers to the probability that an uninfected cow is classified as such. Sensitivity and specificity were calculated as follows:

$$
\begin{gathered}
\text { Sensitivity }(\%)=100 \times \mathrm{TP} /(\mathrm{TP}+\mathrm{FN}) \text {, and } \\
\text { Specificity }(\%)=100 \times \mathrm{TN} /(\mathrm{FP}+\mathrm{TN})
\end{gathered}
$$

The positive predictive value (PPV) is the proportion of cows classified as infected by the model that are actually infected. The negative predictive value (NPV) is the proportion of cows classified as uninfected by the model that are actually uninfected:

$$
\begin{gathered}
\operatorname{PPV}(\%)=100 \times \mathrm{TP} /(\mathrm{TP}+\mathrm{FP}), \text { and } \\
\operatorname{NPV}(\%)=100 \times \mathrm{TN} /(\mathrm{TN}+\mathrm{FN})
\end{gathered}
$$

\section{RESULTS}

The average milk LDH concentration and milk yield in the 2 groups of cows are shown in Table 2. As expected, cows with IMI had a higher milk LDH concentration than uninfected cows. In addition, the variation in milk LDH concentration was higher in infected cows. Values for the variance parameters estimated by the expectation-maximization algorithm converged after 1,000 and 10,000 iterations in the infected and uninfected learning data sets, respectively (Table 2).

\section{Classification of Cows from the Learning Data Sets}

In learning data set 1, all cows were infected. Hence, it was not possible to calculate specificity, but we es- timated the proportion of infected cows classified correctly (sensitivity) to be $58.3 \%(\mathrm{TP}=28, \mathrm{FN}=20)$.

Measurements of LDH and the classification of uninfected cows (learning data set 2) was limited to a 5 -week period. Using the criterion that the probability of infection should be $<0.5$ during all 5 weeks, 28 out of 35 cows were correctly classified as uninfected. When this criterion was changed and we included only the classification result from the fourth and fifth week, 33 of 35 cows were classified correctly. Because all cows in this data set were uninfected, only specificity, which measures the proportion of uninfected cows that are classified correctly, could be estimated. Specificity ranged from 80.0 to $94.3 \%$, depending on which of the above-mentioned criteria were chosen.

\section{Classification of Cows from the Test Data Set}

Out of the 31 cows in the test data set that received antibiotic treatment, 23 had 2 or more negative culture results after treatment. Classification of cows from the test data set gave the following results: $\mathrm{TP}=9, \mathrm{TN}=$ $19, \mathrm{FP}=4, \mathrm{FN}=16$. Thus, the model sensitivity was $36.0 \%$ and specificity was $82.6 \%$. The PPV and NPV were 69.2 and $54.3 \%$, respectively.

Examples of how the model classified cows with different LDH profiles are shown in Figure 1. In Figure 1a, the cow changed status from infected to uninfected after treatment according to the culture results. This was confirmed by the LDH profile, where both level and variation decreased. In this case, the model classified the cow correctly both before and after treatment. This was also the case in Figure 1b, where the cow was infected during the whole period, according to culture results. Infection status was further confirmed by high levels of LDH and variation in LDH. In Figure 1c, the cow was infected before treatment and recovered after treatment, but the LDH profile showed low variation before and after treatment, and the model classified the cow incorrectly as uninfected before treatment. In

\begin{tabular}{|c|c|c|c|c|}
\hline \multirow[b]{2}{*}{ Item } & \multicolumn{2}{|c|}{ Infected } & \multicolumn{2}{|c|}{ Uninfected } \\
\hline & Median & IQR & Median & IQR \\
\hline Milk yield ( $\mathrm{kg}$ of milk) & 30 & 11 & 29 & 12 \\
\hline $\mathrm{LDH}$ concentration $(\mu \mathrm{mol} / \mathrm{min})$ & 2.5 & 4.6 & 1.2 & 1.8 \\
\hline $\mathrm{DIM}^{1}$ & 147 & 265 & 138 & 213 \\
\hline Parity & 2 & 2 & 2 & 2 \\
\hline Estimated observational variance & \multicolumn{2}{|c|}{1.1871} & \multicolumn{2}{|c|}{0.2131} \\
\hline Estimated system variance & \multicolumn{2}{|c|}{0.2442} & \multicolumn{2}{|c|}{0.0065} \\
\hline
\end{tabular}

Table 2. Median and interquartile range (IQR) for milk yield, milk L-lactate dehydrogenase (LDH) concentration, lactation stage, and parity for cows in the 2 learning data sets, together with results of variance parameter estimation for the 2 groups of cows

${ }^{1}$ Calculated at day of treatment for infected group and at day of first culturing for uninfected group. 
Figure 1d, the LDH profile had minimal variation in spite of positive culture results, and the model was unable to classify the cow correctly.

From Figure 1, it is obvious that in some cows, the LDH profile did not clearly indicate infection status. The fact that some infected cows had low LDH levels with small variation and vice versa is also apparent in Figure 2. Measurements of LDH from the TP and TN cows were visibly different: TP cows had higher levels and larger variation in measurements than TN cows. Measurements from cows that were classified incor- rectly, on the other hand, did not follow that pattern: measurements from FP cows showed the highest LDH levels and variations, and it was difficult to distinguish between measurements from TN and FN cows.

We also studied whether the probability of a correct classification after treatment was higher in cows that were classified correctly before treatment. Out of the 28 cows that were classified correctly before treatment, 19 were also classified correctly after treatment, or $67.9 \%$. For this group of cows, sensitivity was $50 \%$ and specificity was $85.7 \%$. Of cows that were classified a)

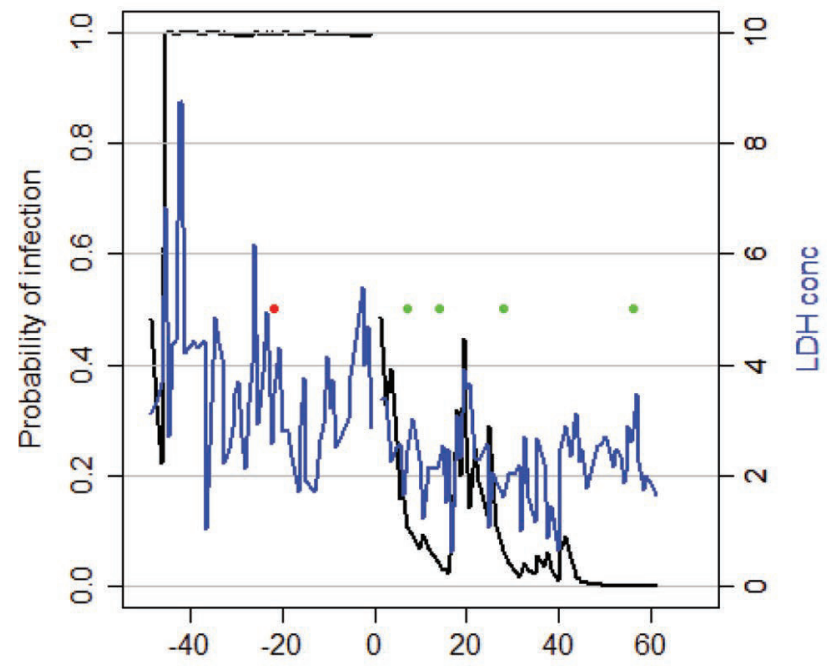

c)

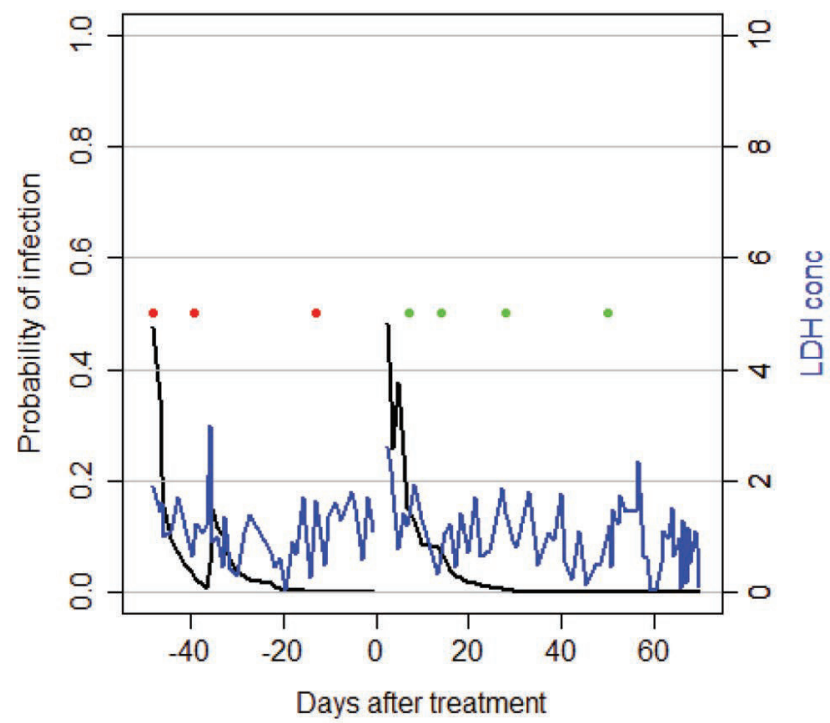

b)

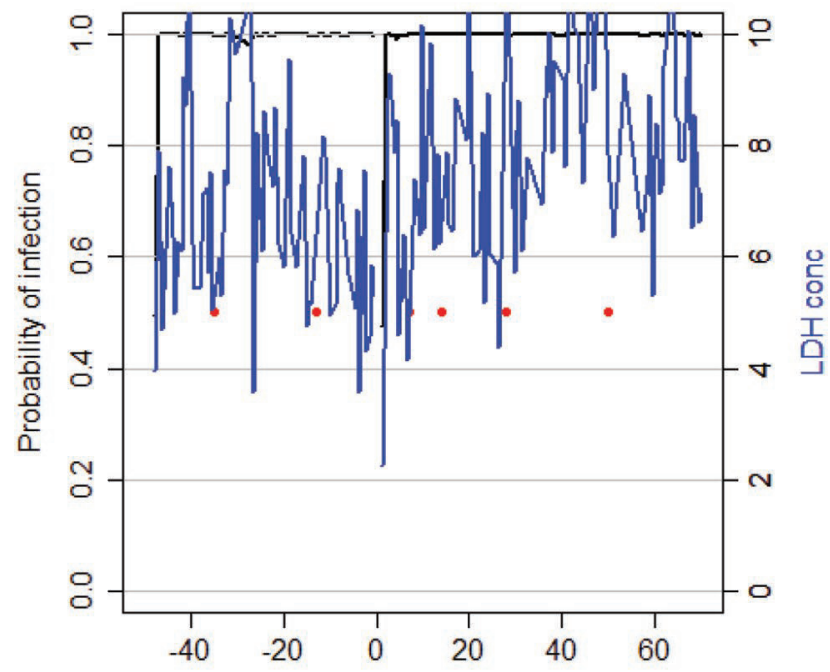

d)

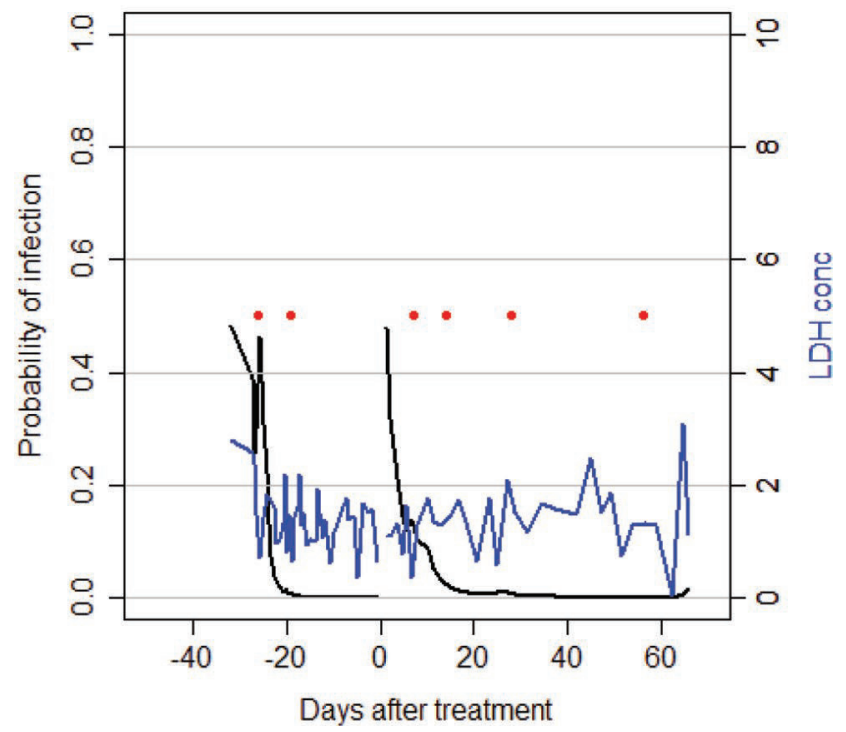

Figure 1. Concentration of L-lactate dehydrogenase (LDH Conc; $\mu \mathrm{mol} / \mathrm{min}$ ) and probability of infection for 4 selected cows during $100 \mathrm{~d}$ around time of treatment. A cow was classified as infected when the probability was $>0.5$ and as uninfected when the probability was $<0.5$. Colored dots indicate bacteriological culturing results (red = positive, green $=$ negative). 


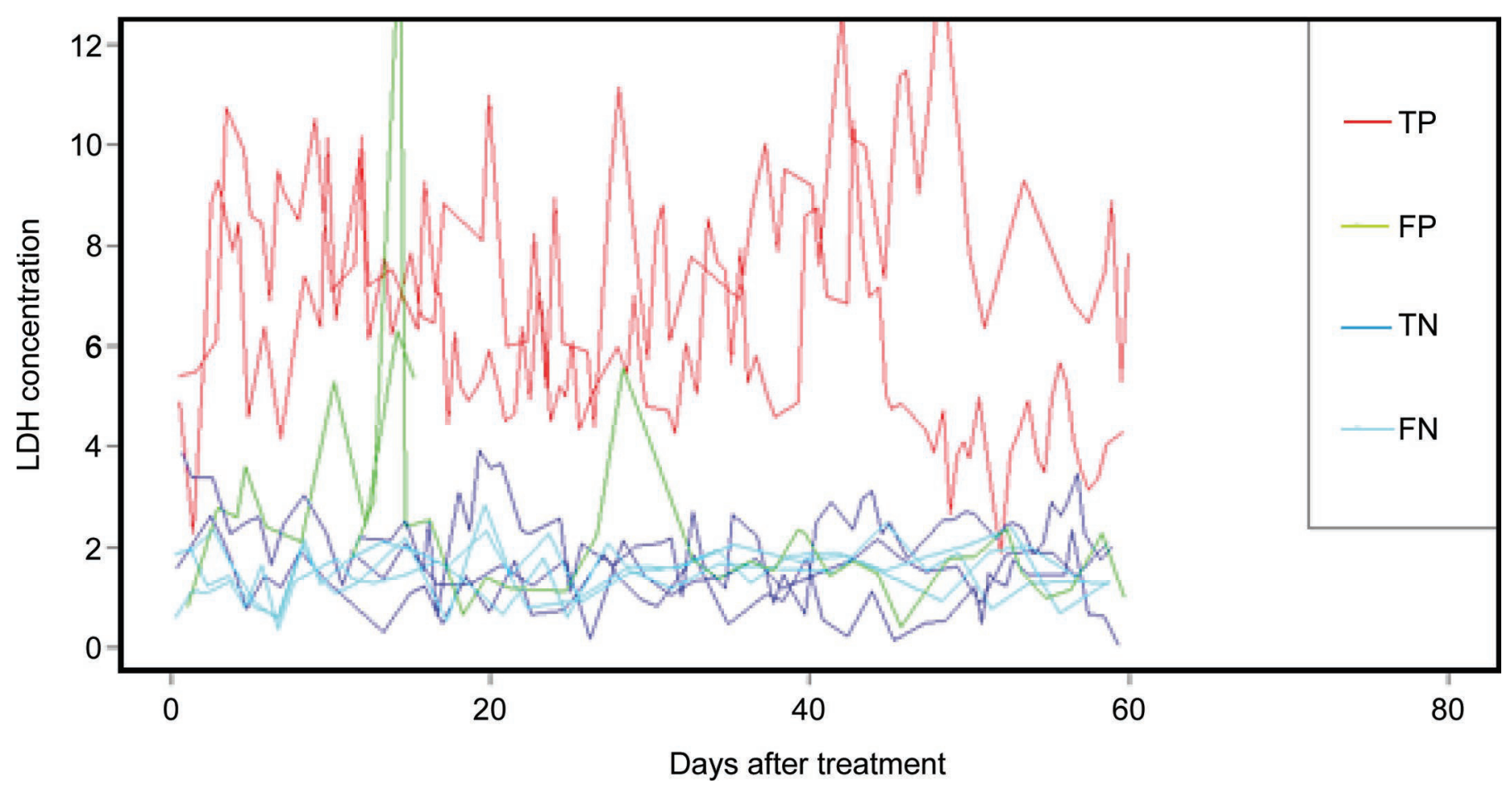

Figure 2. Concentration of L-lactate dehydrogenase ( $\mathrm{LDH} ; \mu \mathrm{mol} / \mathrm{min})$ from 12 selected cows in the test data set, classified as either true positive (TP), false positive (FP), true negative (TN), or false negative (FN).

incorrectly before treatment, only $40.9 \%$ were classified correctly after treatment.

\section{DISCUSSION}

The objective of the present study was to develop a model that could classify cows with former subclinical infections as infected or uninfected after antibiotic treatment when frequent measurements of milk $\mathrm{LDH}$ from individual cows were available. However, our results showed that the infection status of cows included in the present study could not be determined accurately from LDH concentrations in milk by the suggested classification method. The method had very low sensitivity $(36 \%)$, mainly as a result of the relatively high number of $\mathrm{FN}$ and few TP classifications in the test data set. The results of the present study were based only on data from cows with subclinical Staph. aureus infection. In many dairy herds, Staph. aureus is the most prevalent pathogen, but other pathogens are also of great concern. We do not have reason to believe that our conclusions would be different if data from cows with subclinical infections from other pathogens were included in our study.

An ideal system for detection of IMI produces a low number of false alerts. On the other hand, it is also important that the majority of subclinical infections be detected to minimize the risk of contagious transmission. From a practical point of view, it is therefore interesting to know how many cows were classified as uninfected by the model that were actually not infected. In this model, NPV was $54.3 \%$ in the test data set. To be suitable for detection of subclinical infections in practice, the model should have had a higher NPV. If the results from the classification were to be used for separation of infected and uninfected cows to achieve eradication, a high NPV would be especially important to avoid putting infected cows with uninfected cows.

Multiprocess modeling is a method developed for classification. In a class I model like the one used in the present study, classification is based on variation between measurements in the time series. The level of the measurements was not included directly in the model, but accounted for only indirectly. Based on the findings of Chagunda et al. (2006a), we expected level and variation to be related, and this was confirmed by our data (Figure 1). We have reason to believe that the inclusion of measurement levels would not improve the model notably.

The activity of LDH is increased because of IMI (Davis et al., 2004; Fogsgaard et al., 2015). Previous studies have found a strong positive correlation between LDH and SCC (Zank and Schlatterer, 1998; Hiss et al., 2007), and LDH is generally accepted as a useful mas- 
titis indicator. However, the challenge of distinguishing between cows with latent infections and healthy cows based on LDH measurements has been described (Hiss et al., 2007). Attempts have been carried out to create mastitis detection systems using LDH as an indicator of infection. Chagunda et al. (2006b) developed a dynamic deterministic model with sensitivity and specificity for detecting clinical mastitis of 82 and $99 \%$, respectively. In their study, healthy cows were defined as having no veterinary treatment within the current lactation and a SCC $<100,000$ cells $/ \mathrm{mL}$. Cows were defined as having clinical mastitis only if they had a veterinary treatment and a SCC $>400,000$ cells $/ \mathrm{mL}$. Due to this definition, the difference in $\mathrm{LDH}$ response between infected and healthy cows was presumably more noticeable than in our study. Unfortunately, those authors did not mention the LDH activity of the cows.

The model used in the present study classified uninfected cows with great accuracy. These cows had low variation in $\mathrm{LDH}$, as expected for uninfected cows, and it is worth noting that this group was selected based on low SCC. Likewise, the model classified cows with high variation in LDH as infected with good precision. Of cows that were classified correctly before treatment, a larger proportion was also classified correctly after treatment, compared with cows that were classified incorrectly before treatment. The greatest challenge for the model was infected cows with low LDH levels and variation.

There are several plausible explanations why cows with positive culture results can have low a LDH response. The explanation might be found in the bacteriological results: for instance, it is possible that some milk samples tested positive due to contamination of the milk with Staph. aureus originating from the teat skin or the streak canal. However, this was not likely in the present study because cows were identified as infected based on at least 2 consecutive milk samples. The explanation might be also found in host response: we observed a large variation between cows in response to mammary infection with Staph. aureus (Leitner et al., 2000). Some studies suggest that variation can be explained by host characteristics (Wall et al., 2005), but others hypothesize that it is due to differences in pathogenesis between strains of Staph. aureus (Zadoks et al., 2000; Haveri et al., 2005). Thus, cows may be infected with a pathogen that in some cases does not cause inflammation. Finally, the LDH response could be underestimated due to the use of cow composite milk samples, which increases the risk that an infected quarter will be masked owing to dilution effects from healthy quarters.

\section{CONCLUSIONS}

The aim of the present study was to distinguish between infected and recovered cows based on their milk LDH profile after antibiotic treatment. Cows were identified as infected solely based on bacteriological culture results and showed no other signs of infection. The study showed a minor relationship between $\mathrm{LDH}$ and the presence of pathogens in milk and large variation between cows in immune response to subclinical mammary infections. The milk profile of LDH seems to reflect the host response to infection rather than infection itself (i.e., the presence of bacteria in the mammary gland). The variation between cows in immune response to subclinical mammary infection is a great challenge in the detection of subclinically infected cows by use of $\mathrm{LDH}$.

\section{ACKNOWLEDGMENTS}

The study was part of the STOPMAST project (2015-18), which is financially supported by the Danish Milk Levy Fund.

\section{REFERENCES}

Akerstedt, M., L. Forsbäck, T. Larsen, and K. Svennersten-Sjaunja. 2011. Natural variation in biomarkers indicating mastitis in healthy cows. J. Dairy Res. 78:88-96.

Barkema, H. W., Y. H. Schukken, and R. N. Zadoks. 2006. Invited review: The role of cow, pathogen, and treatment regimen in the therapeutic success of bovine Staphylococcus aureus mastitis. J. Dairy Sci. 89:1877-1895.

Bradley, A. 2002. Bovine mastitis: An evolving disease. Vet. J. 164:116-128.

Chagunda, M. G., T. Larsen, M. Bjerring, and K. L. Ingvartsen. 2006a. L-lactate dehydrogenase and N-acetyl-beta-D-glucosaminidase activities in bovine milk as indicators of non-specific mastitis. J. Dairy Res. 73:431-440.

Chagunda, M. G. G., N. C. Friggens, M. D. Rasmussen, and T. Larsen. 2006b. A model for detection of individual cow mastitis based on an indicator measured in milk. J. Dairy Sci. 89:2980-2998.

Cornou, C., and S. Lundbye-Christensen. 2008. Classifying sows' activity types from acceleration patterns: An application of the multi-process Kalman filter. Appl. Anim. Behav. Sci. 111:262-273.

Davis, S. R., V. C. Farr, C. G. Prosser, G. D. Nicholas, S.-A. Turner, J. Lee, and A. L. Hart. 2004. Milk L-lactate concentration is increased during mastitis. J. Dairy Res. 71:175-181.

de Mol, R. M., A. Keen, G. H. Kroeze, and J. M. F. H. Achten. 1999 Description of a detection model for oestrus and diseases in dairy cattle based on time series analysis combined with a Kalman filter. Comput. Electron. Agric. 22:171-185.

Fogsgaard, K. K., P. Løvendahl, T. W. Bennedsgaard, and S. Østergaard. 2015. Changes in milk yield, lactate dehydrogenase, milking frequency, and interquarter yield ratio persist for up to 8 weeks after antibiotic treatment of mastitis. J. Dairy Sci. 98:7686-7698.

Friggens, N. C., M. G. G. Chagunda, M. Bjerring, C. Ridder, S. Højsgaard, and T. Larsen. 2007. Estimating degree of mastitis from time-series measurements in milk: A test of a model based on lactate dehydrogenase measurements. J. Dairy Sci. 90:5415-5427. 
Haveri, M., S. Taponen, J. Vuopio-Varkila, S. Salmenlinna, and S. Pyörälä. 2005. Bacterial genotype affects the manifestation and persistence of bovine Staphylococcus aureus intramammary infection. J. Clin. Microbiol. 43:959-961.

Hiss, S., U. Mueller, A. Neu-Zahren, and H. Sauerwein. 2007. Haptoglobin and lactate dehydrogenase measurements in milk for the identification of subclinically diseased udder quarters. Vet. Med. (Praha) 52:245-252.

Kalman, R. E. 1960. A new approach to linear filtering and prediction problems. J. Basic Eng. 82:35-45.

Kristensen, A. R., E. Jørgensen, and N. Toft. 2010. Dynamic production monitoring by state space models. Pages 75-168 in Herd Management Science. A. R. Kristensen, E. Jørgensen, and N. Toft, ed. Academic Books, Copenhagen, Denmark.

Leitner, G., B. Yadlin, A. Glickman, M. Chaffer, and A. Saran. 2000. Systemic and local immune response of cows to intramammary infection with Staphylococcus aureus. Res. Vet. Sci. 69:181-184.

Lundberg, A. 2015. Mastitis in dairy cows. PhD Thesis. Sveriges Lantbruksuniversitet, Uppsala, Sweden.

Nyman, A. K., U. Emanuelson, and K. P. Waller. 2016. Diagnostic test performance of somatic cell count, lactate dehydrogenase, and $\mathrm{N}$-acetyl- $\beta$-d-glucosaminidase for detecting dairy cows with intramammary infection. J. Dairy Sci. 99:1440-1448.

R Core Team. 2013. R: A Language and Environment for Statistical Computing. R Foundation for Statistical Computing, Vienna, Austria.
Roush, W. B., K. Tomiyama, K. H. Garnaoui, T. H. D'Alfonso, and T. L. Cravener. 1992. Kalman filter and an example of its use to detect changes in poultry production responses. Comput. Electron. Agric. 6:347-356.

Thysen, I. 1993. Monitoring bulk tank somatic cell counts by a multiprocess Kalman filter. Acta Agric. Scand. A. 43:58-64.

Wall, R. J., A. M. Powell, M. J. Paape, D. E. Kerr, D. D. Bannerman, V. G. Pursel, K. D. Wells, N. Talbot, and H. W. Hawk. 2005. Genetically enhanced cows resist intramammary Staphylococcus aureus infection. Nat. Biotechnol. 23:445-451.

West, M., and J. Harrison. 1997. Multi-process models. Pages 427488 in Bayesian Forecasting and Dynamic Models. Springer, New York, NY.

Zadoks, R., W. Van Leeuwen, H. Barkema, O. Sampimon, H. Verbrugh, Y. H. Schukken, and A. Van Belkum. 2000. Application of pulsed-field gel electrophoresis and binary typing as tools in veterinary clinical microbiology and molecular epidemiologic analysis of bovine and human Staphylococcus aureus isolates. J. Clin. Microbiol. 38:1931-1939.

Zank, W. and B. Schlatterer. 1998. Assessment of subacute mammary inflammation by soluble biomarkers in comparison to somatic cell counts in quarter milk samples from dairy cows. J. Vet. Med. 45:41-51. 